\title{
Allocution du Ministre des Affaires culturelles, Monsieur Jean-Noël Tremblay, au banquet du vingtième anniversaire de la Revue d'histoire de l'Amérique française
}

Jean-Noël Tremblay

Volume 21, numéro 1, juin 1967

URI : https://id.erudit.org/iderudit/302642ar

DOI : https://doi.org/10.7202/302642ar

Aller au sommaire du numéro

Éditeur(s)

Institut d'histoire de l'Amérique française

ISSN

0035-2357 (imprimé)

1492-1383 (numérique)

Découvrir la revue

Citer ce document

Tremblay, J.-N. (1967). Allocution du Ministre des Affaires culturelles, Monsieur Jean-Noël Tremblay, au banquet du vingtième anniversaire de la Revue d'histoire de l'Amérique française. Revue d'histoire de l'Amérique française, 21(1), 13-15. https://doi.org/10.7202/302642ar d'utilisation que vous pouvez consulter en ligne. 


\section{Allocution du Ministre des Affaires culturelles Monsieur Jean-Noël Tremblay au banquet du vingtième anniversaire de la Revue d'Histoire de l'Amérique française}

Que vous dirais-je, ce soir, qui exprimerait tout le respect que j'ai pour les chercheurs patients et passionnés qui, depuis des années, s'emploient à ranimer les voix anciennes et à interroger les documents qui racontent la geste de l'Amérique française? Des mots de remerciements? Des félicitations? Ce serait à la fois trop facile et trop banal. Et pourtant! Il me faut user de ces lieux communs: je vous dis done merci, merci du fond du cœur.

Mais cela n'est pas assez. Je voudrais vous rendre un témoignage sans réserve. Témoignage d'admiration et de gratitude parce que, à l'âge de la parole, de la parole à temps et à contretemps, vous vous réservez pour le silence et l'étude, fouillant, scrutant, analysant; vous n'acceptez de parler qu'à l'occasion, quand vos recherches vous ont conduits à un point précis sur le chemin du passé que vous avez le devoir de ressusciter et dont vos articles marquent les jalons.

Votre revue deviendra une somme; elle fournira aux générations qui viennent les renseignements sûrs qu'on chercherait en vain dans les ouvrages prétentieux, dans les "prospectives" hasardeuses des faux savants qui, comme Monsieur Jourdain, font de la poésie sans le savoir en érigeant en dogmes les intuitions de leur esprit tourmenté, et tirent de leur sensibilité les règles d'un "savoir-vivre" qui se veut universel.

Votre œuvre est modeste en apparence; ignorée ici du trop grand nombre et cependant connue à travers le monde. Mais elle est solide; elle sera durable parce qu'elle a des assises qui 
rejoignent notre histoire et sa tradition. Vous ne prétendez pas à "l'essai" - ce mot galvaudé -, vous ne défendez pas de thèses. Vous dites simplement ce qui fut. Commettriez-vous des erreurs que celles-ci seraient salutaires du seul fait que d'autres, après vous, penchés sur les mêmes textes, pourront reprendre votre travail et le compléter avec la même ferveur, la même objectivité et la même honnêteté.

Vous vous êtes attachés à écrire l'histoire de l'Amérique française. Oeuvre collective qui réunit des savants authentiques, des humanistes préoccupés de mettre en lumière les valeurs de notre civilisation. Et l'on vous saura gré de ne pas prêcher. Vous parlez du passé et vous le faites si bien que le lecteur attentif peut prendre la mesure des hommes qui ont bâti notre pays français, ont inspiré sa vie et tracé la ligne du destin de notre communauté.

Il fallait qu'il y eût, à l'origine de cette initiative, une âme dirigeante, une âme de patriote pour qui le patriotisme ne fût pas qu'un thème de discours, mais une vertu. Cette vertu qui est la sagesse de l'enracinement et la conscience lucide d'une identité. Qui contestera que Monsieur le chanoine Groulx a été chez nous l'inspirateur et l'animateur des générations de Canadiens français qui ont cru et croient encore que notre nation avait le droit et le devoir de survivre et de s'épanouir ?

Prophète et guerrier, cet homme n'a jamais pactisé. Il n'a jamais fait appel à la violence; il a défini les responsabilités des nôtres et leur a rappelé sans cesse l'impérieuse nécessité de la fidélité. Il a su, sans verser dans le racisme, insister sur cette vérité que la vocation des Canadiens français consiste pour eux à se réaliser, à atteindre cette perfection essentielle à tout homme dans le milieu que la Providence leur a assigné. Comme tous les hommes de tous les pays, ils ont la mission de témoigner de la vérité et de vivre pleinement, tels qu'ils sont, la fraternité humaine.

Monsieur le chanoine Groulx a senti cette exigence; elle a inspiré et dirigé sa carrière. Aujourd'hui, toujours fort et 
vaillant, il nous demande de veiller encore. Son appel n'a pas été vain. Le nombre de ses disciples le confirme. Il sait toutefois que ceux-ci, témoins de leur temps, emprunteront un autre style et d'autres moyens pour exprimer les impératifs de la fidélité. Qu'il sache cependant que "bon sang ne peut mentir" et que pour se traduire autrement, ses leçons ne seront pas oubliées. Les collaborateurs qui l'entourent et qui l'ont suivi ne démériteront pas, parce qu'ils ont appris à son contact qu'il est des valeurs qui transcendent les modes et les travers contemporains. Il y a une façon de respecter le passé qui n'est ni reniement ni apostasie; il suffit qu'il y ait accord de la tradition avec le progrès.

Ainsi, Mesdames et Messieurs, en vous associant à Monsieur le chanoine Groulx, je sais que je n'enlève rien à personne et que les remerciements et les félicitations que je lui adresse sont à vos yeux un hommage collectif. Au nom du gouvernement du Québec, je salue l'équipe de la Revue d'Histoire de l'Amérique française, je lui souhaite longue vie en l'assurant de la sollicitude toute particulière du ministère des Affaires culturelles. Vous avez bien mérité de la Patrie parce que vous dites si bien la Patrie. $\AA$ ceux d'hier et d'aujourd'hui, à tous les artisans de la revalorisation du patrimoine, mes plus fervents hommages.

JEAN-NoËL TREMbLAY, Ministre des Affaires culturelles du Québec 